\title{
STRONG CONVERGENCE OF A MODIFIED ISHIKAWA ITERATIVE ALGORITHM FOR LIPSCHITZ PSEUDOCONTRACTIVE MAPPINGS
}

\author{
M.O. OSILIKE* ${ }^{*}$ F.O. ISIOGUGU AND F.U. ATTAH
}

\begin{abstract}
Let $H$ be a real Hilbert space and let $T: H \rightarrow H$ be a Lipschitz pseudocontractive mapping. We introduce a modified Ishikawa iterative algorithm and prove that if $F(T)=\{x \in H: T x=x\} \neq \emptyset$, then our proposed iterative algorithm converges strongly to a fixed point of $T$. No compactness assumption is imposed on $T$ and no further requirement is imposed on $F(T)$.
\end{abstract}

AMS Mathematics Subject Classification : 47J25, 47H09, 65J15.

Key words and phrases : Pseudocontractive maps, fixed points, Ishikawa iteration, strong convergence, Hilbert spaces.

\section{Introduction}

Let $H$ be a real Hilbert space with inner product $\langle.,$.$\rangle and induced norm \|$.$\| .$ Let $C$ be a nonempty closed convex subset of $\mathrm{H}$. A mapping $T: C \rightarrow C$ is said to be $L$-Lipschitzian if there exists $L \geq 0$ such that

$$
\|T x-T y\| \leq L\|x-y\|, \forall x, y \in C .
$$

$T$ is said to be a contraction if $L \in[0,1)$ and $T$ is said to be nonexpansive if $L=1 . T$ is said to be pseudocontractive in the terminology of Browder and Petryshyn [1] if

$$
\|T x-T y\|^{2} \leq\|x-y\|^{2}+\|x-T x-(y-T y)\|^{2}, \forall x, y \in C .
$$

It is easy to verify that (1.1) is equivalent to the monotonicity condition

$$
\langle(I-T) x-(I-T) y, x-y\rangle \geq 0, \forall x, y \in C,
$$

Received September 2, 2012. Revised September 24, 2012. Accepted October 11, 2012. ${ }^{*}$ Corresponding author.

(c) 2013 Korean SIGCAM and KSCAM. 
where $I$ is the identity operator. Inequalities (1.2) and (1.3) are also equivalent to the inequality

$$
\langle T x-T y, x-y\rangle \leq\|x-y\|^{2}, \forall x, y \in C .
$$

An important proper subclass of the class of pseudocontractive mappings is the class of $k$-strictly pseudocontractive mappings. $T$ is said to be $k$-strictly pseudocontractive (see for example [1]) if there exists $k \in[0,1)$ such that

$$
\|T x-T y\|^{2} \leq\|x-y\|^{2}+k\|x-T x-(y-T y)\|^{2}, \forall x, y \in C
$$

It is well known that if $T$ is $k$-strictly pseudocontractive, then $T$ is Lipschitz with Lipschitz constant $L=\frac{1+\sqrt{k}}{1-\sqrt{k}}$.

If $F(T)=\{x \in C: T x=x\} \neq \emptyset$ and inequality (1.2) (or (1.3) or (1.4)) is satisfied for all $x \in C$ and for all $y \in F(T)$, then $T$ is said to be hemicontractive (see for example [2]). $T$ is said to be demicontractive if $F(T) \neq \emptyset$ and inequality (1.5) is satisfied for some $k \in[0,1)$ and for all $x \in C$, and $y \in F(T)$. $T$ is said to be demiclosed at $p$ if whenever $\left\{x_{n}\right\}_{n=1}^{\infty}$ is a sequence in $C$ which converges weakly to $x^{*} \in C$ and $\left\{T x_{n}\right\}_{n=1}^{\infty}$ converges strongly to $p$, then $T x^{*}=p$.

The Mann iteration scheme $\left\{x_{n}\right\}_{n=1}^{\infty}$ generated from an arbitrary $x_{1} \in C$ by

$$
x_{n+1}=\left(1-\alpha_{n}\right) x_{n}+\alpha_{n} T x_{n}, n \geq 1,
$$

where the control sequence $\left\{\alpha_{n}\right\}_{n=1}^{\infty}$ is a real sequence in [0,1] satisfying some appropriate conditions has been used by several authors for the approximation of fixed points of nonexpansive maps, strictly pseudocontractive maps and demicontractive maps (see for example [1-8]). It is now well known (see for example [9]) that Mann iteration scheme may not in general be applicable for the iterative construction of fixed points of a Lipschitz pseudocontractive map in Hilbert spaces. For Lipschitz pseudocontractive maps, the Ishikawa iteration sequence $\left\{x_{n}\right\}_{n=1}^{\infty}$ generated from arbitrary $x_{1} \in C$ by

$$
x_{n+1}=\left(1-\alpha_{n}\right) x_{n}+\alpha_{n} T\left[\left(1-\beta_{n}\right) x_{n}+\beta_{n} T x_{n}\right], n \geq 1,
$$

where $\left\{\alpha_{n}\right\}$ and $\left\{\beta_{n}\right\}$ are control sequences in $[0,1]$ is usually applicable.

In real Hilbert spaces, one of the most general well known convergence theorem using the Mann iteration algorithm for the class of $k$-strictly pseudocontractive mappings is the following.

Theorem 1.1 ([10]). Let $H$ be a real Hilbert space and let $C$ be a nonempty closed convex subset of $H$. Let $T: C \rightarrow C$ be a k-strictly pseudocontractive map with a nonempty fixed point set $F(T)$ and let $\left\{\alpha_{n}\right\}_{n=1}^{\infty}$ be a real sequence in $(0,1-k)$ satisfying the conditions (i) $\lim _{n \rightarrow \infty} \alpha_{n}=0$ (ii) $\sum_{n=1}^{\infty} \alpha_{n}\left(1-\alpha_{n}-k\right)=$ $\infty$. Then the Mann iteration algorithm $\left\{x_{n}\right\}_{n=1}^{\infty}$ converges weakly to a fixed point of $T$.

If $k=0$ in Theorem 1.1, we obtain weak convergence theorem for nonexpansive maps. 
To obtain strong convergence of Mann to a fixed of a $k$-strictly pseudocontractive maps or even a nonexpansive map in the setting of Theorem 1.1, additional conditions are usually required on $T$ or the subset $C$ (see for example [1-8]). In [11], Genel and Lindenstraus provided an example of a nonexpansive mapping defined on a bounded closed convex subset of a Hilbert space for which the Mann iteration does not converge to a fixed point of $T$.

Recently Yao, Zhou and Liou [12] (see also [13]) studied a modified Mann iteration algorithm and proved strong convergence of the modified algorithm to a fixed point of a nonexpansive mapping in real Hilbert spaces. They proved the following.

Theorem 1.2 Let $H$ be a real Hilbert space. Let $T: H \rightarrow H$ be a non-expansive mapping with $F(T) \neq \emptyset$. Let $\left\{t_{n}\right\}_{n=1}^{\infty}$ and $\left\{\alpha_{n}\right\}_{n=1}^{\infty}$ be two real sequences in $[0,1]$. Assume the following conditions are satisfied:

(c1) $\lim _{n \rightarrow \infty} t_{n}=0$;

(c2) $\sum_{n=1}^{n \rightarrow \infty} t_{n}=\infty$;

(c3) $\alpha_{n} \in[a, b] \subset(0,1)$.

Then the modified Mann iteration sequence $\left\{x_{n}\right\}_{n=1}^{\infty}$ generated from an arbitrary $x_{1} \in H$ by

$$
x_{n+1}=\left(1-\alpha_{n}\right)\left(1-t_{n}\right) x_{n}+\alpha_{n} T\left[\left(1-t_{n}\right) x_{n}\right], n \geq 1
$$

converges strongly to a fixed point of $T$.

Observe that $\left\{x_{n}\right\}$ can be expressed in the form

$$
\left\{\begin{array}{l}
\nu_{n}=\left(1-t_{n}\right) x_{n} \\
x_{n+1}=\left(1-\alpha_{n}\right) \nu_{n}+\alpha_{n} T \nu_{n}
\end{array}\right.
$$

Clearly, the modified Mann iteration algorithm reduces to the normal Mann iteration algorithm when $t_{n} \equiv 0$.

More recently, Paul-Emile Maingé and Ştefan Măruşter [14] employed the modified Mann algorithm (1.8) and proved that it converges strongly to a fixed point of a demicontractive map in real Hilbert spaces. They proved the following:

Theorem 1.3 Let $H$ be a real Hilbert space and let $T: H \rightarrow H$ be a demicontractive map with constant $k \in[0,1)$ and let $(I-T)$ be demiclosed at 0 . Let $\left\{t_{n}\right\}_{n=1}^{\infty}$ and $\left\{\alpha_{n}\right\}_{n=1}^{\infty}$ be two real numbers in $[0,1]$. Assume the following conditions are satisfied:

(c1) $\lim _{n \rightarrow \infty} t_{n}=0$;

(c2) $\sum_{n=1}^{n \rightarrow \infty} t_{n}=\infty$;

(c3) $\left\{\alpha_{n}\right\} \subset(0, b]$, with $0<b<1-k$;

(c4) $\lim _{n \rightarrow \infty} \frac{t_{n}}{\alpha_{n}}=0$.

Then the modified Mann iteration sequence $\left\{x_{n}\right\}_{n=1}^{\infty}$ generated from an $x_{1} \in H$ by (1.8) converges strongly to $P_{F(T)}(0)$ the least norm element of $F(T)$. 
For $L$-Lipschitzian pseudocontractive maps for which the Ishikawa algorithm rather than the Mann algorithm has been applicable, Ishikawa [15] first proved the following:

Theorem 1.4 Let $C$ be a nonempty compact subset of a real Hilbert space $H$ and $T: C \rightarrow C$ an L-Lipschitzian pseudocontractive mapping. Let $\left\{\alpha_{n}\right\}_{n=1}^{\infty}$ and $\left\{\beta_{n}\right\}_{n=1}^{\infty}$ be real sequences satisfying the conditions:

(i) $0 \leq \alpha_{n} \leq \beta_{n}<1$; (ii) $\lim _{n \rightarrow \infty} \beta_{n}=0$; (iii) $\sum_{n=1}^{\infty} \alpha_{n} \beta_{n}=\infty$. Then the Ishikawa iteration sequence $\left\{\begin{array}{l}n \rightarrow \infty \\ \left.x_{n}\right\}_{n=1}^{\infty}\end{array}\right.$ generated from an arbitrary $x_{1} \in C$ by (1.7) converges strongly to a fixed point of $T$.

Since the appearance of Theorem 1.4, many authors have extended it in various forms (see for example [16-23]). However, strong convergence have not been achieved without compactness assumption on $T$ or $C$; or other requirements on the set of fixed point $F(T)$; or complete modification of the scheme to a hybrid algorithm (see for examples [16-23]). Recently, Zegeye, Shahzad and Alghamdi [17] assumed that the interior of $F(T)$ is nonempty $(\operatorname{int} F(T) \neq \emptyset)$ to achieve strong convergence when $T$ is a self mapping of a nonempty closed convex subset of a real Hilbert space. This appears very restrictive since even in $\Re$ with the usual norm, Lipschitz pseudocontractive maps with finite number of fixed points do not enjoy this condition that $\operatorname{int} F(T) \neq \emptyset$.

It is our purpose in this paper to complement Yao, $\mathrm{Xu}$ and Liou [12]; and Maingé and Măruşter [14] by introducing a modified Ishikawa iteration algorithm analogous to the modified Mann iteration algorithm studied in [12] and [14]. We further prove that our modified Ishikawa algorithm converges strongly to a fixed point of a Lipschitz pseodocontive map in real Hilbert spaces.

\section{Preliminaries}

In what follows, we shall need the following results.

Lemma 2.1 ([Kolmogorov Criterium]). Let $C$ be a closed convex subset of a real Hilbert space $H$ and let $x$ be a point in $H$. Let $P_{C}(x)$ denote the projection of $x$ onto $C$. Then $z=P_{C}(x)$ if and only if $\langle x-z, z-y\rangle \geq 0, \forall y \in C$.

Lemma 2.1 ([24]). Let $H$ be a real Hilbert space, $C$ a closed convex subset of $H$ and $T: C \rightarrow C$ a continuous pseudocontractive mapping, then

(i) $F(T)$ is a closed convex subset of $C$.

(ii) $(I-T)$ is demiclosed at zero.

Lemma $2.2([14])$. Let $\left\{a_{n}\right\}$ be a sequence of nonnegative numbers such that $a_{n+1} \leq\left(1-\lambda_{n}\right) a_{n}+\lambda_{n} r_{n}$, where $\left\{r_{n}\right\}$ is a bounded sequence of real numbers and $\left\{\lambda_{n}\right\} \subset[0,1]$ satisfies $\sum_{n=1}^{\infty} \lambda_{n}=\infty$. Then $\limsup _{n \rightarrow \infty} a_{n} \leq \limsup _{n \rightarrow \infty} r_{n}$.

\section{Main results}

We now introduce the following modified form of the Ishikawa algorithm: 
Modified Ishikawa Algorithm. Let $H$ be a real Hilbert space and let $T$ : $H \rightarrow H$ be a giving mapping. For arbitrary $x_{1} \in H$ our modified Ishikawa iteration sequence $\left\{x_{n}\right\}$ is given by

$x_{n+1}=\left(1-\alpha_{n}\right)\left(1-t_{n}\right) x_{n}+\alpha_{n} T\left[\left(1-\beta_{n}\right)\left(1-t_{n}\right) x_{n}+\beta_{n} T\left[\left(1-t_{n}\right) x_{n}\right]\right], n \geq 1$

where $\left\{t_{n}\right\},\left\{\alpha_{n}\right\}$ and $\left\{\beta_{n}\right\}$ are real sequences in $[0,1]$ satisfying some appropriate conditions that will be made precise in our strong convergence theorem. Observe that (3.1) can be written in the form

$$
\left\{\begin{array}{l}
\nu_{n}=\left(1-t_{n}\right) x_{n} \\
y_{n}=\left(1-\beta_{n}\right) \nu_{n}+\beta_{n} T \nu_{n} \\
x_{n+1}=\left(1-\alpha_{n}\right) \nu_{n}+\alpha_{n} T y_{n}
\end{array}\right.
$$

Observe that as in the case of the modified Mann iteration algorithm of [12] and [14], our modified Ishikawa iteration scheme reduces to the normal Ishikawa iteration when $t_{n} \equiv 0$.

We now prove the following strong convergence theorems which applies for $L$-Lipschitzian pseudocontractive maps in real Hilbert spaces.

Theorem 3.1 Let $H$ be a real Hilbert space and let $T: H \rightarrow H$ be an $L$ Lipschitzian hemicontractive map such that $(I-T)$ is demiclosed at 0. Let $\left\{t_{n}\right\}_{n=1}^{\infty},\left\{\alpha_{n}\right\}_{n=1}^{\infty}$ and $\left\{\beta_{n}\right\}$ be sequences in $(0,1)$ satisfying the conditions

(c1) $\lim _{n \rightarrow \infty} t_{n}=0$;

(c2) $\sum_{n=1}^{n \rightarrow \infty} t_{n}=\infty$;

(c3) $\alpha_{n} \leq \beta_{n}, n \geq 1$; and $0<\epsilon \leq \beta_{n} \leq b<1$ for some $\epsilon>0$ and for some $b \in\left(0, \frac{1}{\sqrt{1+L^{2}}+1}\right)$;

(c4) $\lim _{n \rightarrow \infty} \frac{t_{n}}{\alpha_{n}}=0$.

Then the modified Ishikawa iteration sequence $\left\{x_{n}\right\}_{n=1}^{\infty}$ generated from an $x_{1} \in$ $H$ by (3.1) converges strongly to $P_{F(T)}(0)$ the least norm element of $F(T)$.

Proof. Using the form (3.2) we set $G_{n} \nu_{n}:=T\left[\left(1-\beta_{n}\right) \nu_{n}+\beta_{n} T \nu_{n}\right], n \geq 1$. Then using the Lipschitz property of $T$ and the well known identity

$$
\|(1-t) x+t y\|^{2}=(1-t)\|x\|^{2}+t\|y\|^{2}-t(1-t)\|x-y\|^{2}
$$

which holds for all $x, y$ in $H$ and for all $t$ in $[0,1]$ we obtain for arbitrary $p \in F(T)$ that

$$
\begin{aligned}
\left\|G_{n} \nu_{n}-p\right\|^{2}= & \left\|T\left[\left(1-\beta_{n}\right) \nu_{n}+\beta_{n} T \nu_{n}\right]-p\right\|^{2} \\
\leq & \left\|\left(1-\beta_{n}\right) \nu_{n}+\beta_{n} T \nu_{n}-p\right\|^{2}+\left\|\left(1-\beta_{n}\right) \nu_{n}+\beta_{n} T \nu_{n}-G_{n} \nu_{n}\right\|^{2} \\
= & \left\|\left(1-\beta_{n}\right)\left(\nu_{n}-p\right)+\beta_{n}\left(T \nu_{n}-p\right)\right\|^{2} \\
& +\left\|\left(1-\beta_{n}\right)\left(\nu_{n}-G_{n} \nu_{n}\right)+\beta_{n}\left(T \nu_{n}-T\left[\left(1-\beta_{n}\right) \nu_{n}+\beta_{n} T \nu_{n}\right]\right)\right\|^{2} \\
= & \left(1-\beta_{n}\right)\left\|\nu_{n}-p\right\|^{2}+\beta_{n}\left\|T \nu_{n}-p\right\|^{2}-\beta_{n}\left(1-\beta_{n}\right)\left\|\nu_{n}-T \nu_{n}\right\|^{2} \\
& +\left(1-\beta_{n}\right)\left\|\nu_{n}-G_{n} \nu_{n}\right\|^{2}
\end{aligned}
$$




$$
\begin{aligned}
& +\beta_{n}\left\|T \nu_{n}-T\left[\left(1-\beta_{n}\right) \nu_{n}+\beta_{n} T \nu_{n}\right]\right\|^{2} \\
& -\beta_{n}\left(1-\beta_{n}\right)\left\|\nu_{n}-T \nu_{n}\right\|^{2} \\
\leq & \left\|\nu_{n}-p\right\|^{2}+\beta_{n}\left\|\nu_{n}-T \nu_{n}\right\|^{2}-\beta_{n}\left(1-\beta_{n}\right)\left\|\nu_{n}-T \nu_{n}\right\|^{2} \\
& +\left(1-\beta_{n}\right)\left\|\nu_{n}-G_{n} \nu_{n}\right\|^{2}+L^{2} \beta_{n}^{3}\left\|\nu_{n}-T \nu_{n}\right\|^{2} \\
& -\beta_{n}\left(1-\beta_{n}\right)\left\|\nu_{n}-T \nu_{n}\right\|^{2} \\
= & \left\|\nu_{n}-p\right\|^{2}+\left(1-\beta_{n}\right)\left\|\nu_{n}-G_{n} \nu_{n}\right\|^{2} \\
& -\beta_{n}\left[1-2 \beta_{n}-\beta_{n}^{2} L^{2}\right]\left\|\nu_{n}-T \nu_{n}\right\|^{2} .
\end{aligned}
$$

Using (3.4) we obtain for arbitrary $p \in F(T)$ that

$$
\begin{aligned}
\left\|x_{n+1}-p\right\|^{2}= & \left\|\left(1-\alpha_{n}\right)\left(\nu_{n}-p\right)+\alpha_{n}\left(G_{n} \nu_{n}-p\right)\right\|^{2} \\
= & \left(1-\alpha_{n}\right)\left\|\nu_{n}-p\right\|^{2}+\alpha_{n}\left\|G_{n} \nu_{n}-p\right\|^{2} \\
& -\alpha_{n}\left(1-\alpha_{n}\right)\left\|\nu_{n}-G_{n} \nu_{n}\right\|^{2} \\
\leq & \left(1-\alpha_{n}\right)\left\|\nu_{n}-p\right\|^{2}+\alpha_{n}\left[\left\|\nu_{n}-p\right\|^{2}\right. \\
& \left.+\left(1-\beta_{n}\right)\left\|\nu_{n}-G_{n} \nu_{n}\right\|^{2}-\beta_{n}\left(1-2 \beta_{n}-\beta_{n}^{2} L^{2}\right)\left\|\nu_{n}-T \nu_{n}\right\|^{2}\right] \\
& -\alpha_{n}\left(1-\alpha_{n}\right)\left\|\nu_{n}-G_{n} \nu_{n}\right\|^{2} \\
= & \left\|\nu_{n}-p\right\|^{2}-\alpha_{n}\left(\beta_{n}-\alpha_{n}\right)\left\|\nu_{n}-G_{n} \nu_{n}\right\|^{2} \\
& -\alpha_{n} \beta_{n}\left[1-2 \beta_{n}-\beta_{n}^{2} L^{2}\right]\left\|\nu_{n}-T \nu_{n}\right\|^{2} .
\end{aligned}
$$

Since $\alpha_{n} \leq \beta_{n}, \forall n \geq 1$, we obtain

$$
\left\|x_{n+1}-p\right\|^{2} \leq\left\|\nu_{n}-p\right\|^{2}-\alpha_{n} \beta_{n}\left[1-2 \beta_{n}-\beta_{n}^{2} L^{2}\right]\left\|\nu_{n}-T \nu_{n}\right\|^{2} .
$$

From (3.2) we obtain $\frac{1}{\alpha_{n}}\left(\nu_{n}-x_{n+1}\right)=\nu_{n}-G_{n} \nu_{n}$. Hence

$$
\begin{aligned}
\frac{1}{\alpha_{n}}\left\|\nu_{n}-x_{n+1}\right\| & =\left\|\nu_{n}-G_{n} \nu_{n}\right\| \\
& \leq\left\|\nu_{n}-T \nu_{n}\right\|+\left\|T \nu_{n}-G_{n} \nu_{n}\right\| \\
& \leq\left\|\nu_{n}-T \nu_{n}\right\|+L \beta_{n}\left\|\nu_{n}-T \nu_{n}\right\| \\
& =\left[1+L \beta_{n}\right]\left\|\nu_{n}-T \nu_{n}\right\| .
\end{aligned}
$$

Thus

$$
\frac{1}{\alpha_{n}\left(1+L \beta_{n}\right)}\left\|\nu_{n}-x_{n+1}\right\| \leq\left\|\nu_{n}-T \nu_{n}\right\| .
$$

Using (3.8) in (3.7) we obtain

$$
\left\|x_{n+1}-p\right\|^{2} \leq\left\|\nu_{n}-p\right\|^{2}-\lambda_{n}\left\|\nu_{n}-x_{n+1}\right\|^{2},
$$

where

$$
\lambda_{n}:=\frac{\beta_{n}\left[1-2 \beta_{n}-L^{2} \beta_{n}^{2}\right]}{\alpha_{n}\left(1+L \beta_{n}\right)^{2}} \geq \frac{\epsilon\left[1-2 b-L^{2} b^{2}\right]}{b(1+L b)^{2}}>0 .
$$

Furthermore, it follows from (3.2) and (3.9) that

$$
\left\|x_{n+1}-p\right\| \leq\left\|\nu_{n}-p\right\| \leq\left(1-t_{n}\right)\left\|x_{n}-p\right\|+t_{n}\|p\|,
$$


and this yields

$$
\left\|x_{n+1}-p\right\| \leq \max \left\{\left\|x_{1}-p\right\|,\|p\|\right\} .
$$

Hence $\left\{x_{n}\right\}_{n=1}^{\infty}$ is a bounded sequence.

It also follows from (3.2) that

$$
\begin{aligned}
\left\|\nu_{n}-p\right\|^{2} & =\left\|\left(1-t_{n}\right)\left(x_{n}-p\right)-t_{n} p\right\|^{2} \\
& =\left(1-t_{n}\right)^{2}\left\|x_{n}-p\right\|^{2}+t_{n}^{2}\|p\|^{2}-2 t_{n}\left(1-t_{n}\right)\left\langle x_{n}-p, p\right\rangle \\
& \leq\left(1-t_{n}\right)\left\|x_{n}-p\right\|^{2}+t_{n}^{2}\|p\|^{2}-2 t_{n}\left(1-t_{n}\right)\left\langle x_{n}-p, p\right\rangle .
\end{aligned}
$$

Using (3.10) in (3.9) we obtain

$$
\begin{aligned}
\left\|x_{n+1}-p\right\|^{2} \leq & \left(1-t_{n}\right)\left\|x_{n}-p\right\|^{2}+t_{n}^{2}\|p\|^{2}-2 t_{n}\left(1-t_{n}\right)\left\langle x_{n}-p, p\right\rangle \\
& -\lambda_{n}\left\|\nu_{n}-x_{n+1}\right\|^{2} \\
= & \left(1-t_{n}\right)\left\|x_{n}-p\right\|^{2}-t_{n}\left[-t_{n}\|p\|^{2}+2\left(1-t_{n}\right)\left\langle x_{n}-p, p\right\rangle\right. \\
& \left.+\frac{\lambda_{n}}{t_{n}}\left\|\nu_{n}-x_{n+1}\right\|^{2}\right] \\
= & \left(1-t_{n}\right)\left\|x_{n}-p\right\|^{2}-t_{n} Z_{n},
\end{aligned}
$$

where

$$
Z_{n}:=-t_{n}\|p\|^{2}+2\left(1-t_{n}\right)\left\langle x_{n}-p, p\right\rangle+\frac{\lambda_{n}}{t_{n}}\left\|\nu_{n}-x_{n+1}\right\|^{2} .
$$

Thus,

$$
\left\|x_{n+1}-p\right\|^{2} \leq\left(1-t_{n}\right)\left\|x_{n}-p\right\|^{2}-t_{n} Z_{n} .
$$

Observe that

$$
\begin{aligned}
-Z_{n} & =t_{n}\|p\|^{2}-2\left(1-t_{n}\right)\left\langle x_{n}-p, p\right\rangle-\frac{\lambda_{n}}{t_{n}}\left\|\nu_{n}-x_{n+1}\right\|^{2} \\
& \leq\|p\|^{2}+2\left\|x_{n}-p\right\|\|p\| \leq D_{1} \text {, for some } D_{1} \text {, since }\left\{x_{n}\right\} \text { is bounded. }
\end{aligned}
$$

It thus follows that $\left\{Z_{n}\right\}$ is bounded below since $\left\{x_{n}\right\}$ is bounded. From (3.13), Lemma 2.3 and condition (c2) of our theorem we obtain

$$
\limsup _{n \rightarrow \infty}\left\|x_{n}-p\right\|^{2} \leq \limsup _{n \rightarrow \infty}\left(-Z_{n}\right)=-\liminf _{n \rightarrow \infty} Z_{n} .
$$

Thus $\liminf _{n \rightarrow \infty} Z_{n}$ is a finite real number. Since $\lim _{n \rightarrow \infty} t_{n}=0$, it follows from (3.12) that

$$
\liminf _{n \rightarrow \infty} Z_{n}=\liminf _{n \rightarrow \infty}\left[2\left\langle x_{n}-p, p\right\rangle+\frac{\lambda_{n}}{t_{n}}\left\|\nu_{n}-x_{n+1}\right\|^{2}\right] .
$$

Since $\left\{x_{n}\right\}$ is bounded, there exists a subsequence $\left\{x_{n_{k}}\right\}_{k=1}^{\infty}$ of $\left\{x_{n}\right\}$ such that

$$
\liminf _{n \rightarrow \infty} Z_{n}=\lim _{k \rightarrow \infty}\left[2\left\langle x_{n_{k}}-p, p\right\rangle+\frac{\lambda_{n_{k}}}{t_{n_{k}}}\left\|\nu_{n_{k}}-x_{n_{k}+1}\right\|^{2}\right] .
$$


Since $\left\{x_{n}\right\}$ is bounded and $\liminf _{n \rightarrow \infty} Z_{n}$ is finite, it follows that $\frac{\lambda_{n_{k}}}{t_{n_{k}}}\left\|\nu_{n_{k}}-x_{n_{k}+1}\right\|^{2}$ is bounded. Observe that since

$$
\frac{\lambda_{n}}{t_{n}}=\frac{\beta_{n}\left[1-2 \beta_{n}-L^{2} \beta_{n}^{2}\right]}{\alpha_{n} t_{n}\left(1+L \beta_{n}\right)^{2}} \geq \frac{\epsilon\left[1-2 b-L^{2} b^{2}\right]}{\alpha_{n} t_{n}(1+L b)^{2}},
$$

then

$$
\frac{1}{\alpha_{n} t_{n}} \leq \frac{(1+L b)^{2} \lambda_{n}}{\epsilon\left[1-2 b-L^{2} L^{2}\right] t_{n}}
$$

Thus

$$
\frac{1}{\alpha_{n_{k}} t_{n_{k}}}\left\|\nu_{n_{k}}-x_{n_{k}+1}\right\|^{2} \leq \frac{(1+L b)^{2}}{\epsilon\left[1-2 b-L^{2} b^{2}\right]} \frac{\lambda_{n_{k}}}{t_{n_{k}}}\left\|v_{n_{k}}-x_{n_{k}+1}\right\|^{2} .
$$

Hence $\frac{1}{\alpha_{n_{k}} t_{n_{k}}}\left\|\nu_{n_{k}}-x_{n_{k}+1}\right\|^{2}$ is bounded. Observe that from (3.2) we have $\frac{1}{\alpha_{n}}\left(\nu_{n}-x_{n+1}\right)=\nu_{n}-G_{n} \nu_{n}$. Hence

$$
\begin{aligned}
\frac{1}{\alpha_{n}}\left\|\nu_{n}-x_{n+1}\right\| & =\left\|\nu_{n}-G_{n} \nu_{n}\right\| \\
& \geq\left|\left\|\nu_{n}-T \nu_{n}\right\|-\left\|T \nu_{n}-G_{n} \nu_{n}\right\|\right| \\
& \geq\left\|\nu_{n}-T \nu_{n}\right\|-L \beta_{n}\left\|\nu_{n}-T \nu_{n}\right\| \\
& =\left[1-L \beta_{n}\right]\left\|\nu_{n}-T \nu_{n}\right\| .
\end{aligned}
$$

Thus

$$
\left\|\nu_{n}-T \nu_{n}\right\| \leq \frac{1}{\alpha_{n}\left(1-L \beta_{n}\right)}\left\|\nu_{n}-x_{n+1}\right\| \leq \frac{1}{\alpha_{n}(1-L b)}\left\|\nu_{n}-x_{n+1}\right\| .
$$

It now follows that

$$
\left\|\nu_{n}-T \nu_{n}\right\|^{2} \leq \frac{t_{n}}{\alpha_{n}}\left(\frac{1}{(1-L b)^{2}} \frac{\left\|\nu_{n}-x_{n+1}\right\|^{2}}{\alpha_{n} t_{n}}\right) .
$$

Furthermore

$$
\begin{aligned}
\left\|x_{n}-x_{n+1}\right\| & \leq\left\|x_{n}-\nu_{n}\right\|+\left\|\nu_{n}-x_{n+1}\right\| \\
& \leq t_{n}\left\|x_{n}\right\|+\alpha_{n}\left\|\nu_{n}-T y_{n}\right\| \\
& \leq t_{n}\left\|x_{n}\right\|+\left\|\nu_{n}-T \nu_{n}\right\|+L\left\|\nu_{n}-T \nu_{n}\right\| \\
& =t_{n}\left\|x_{n}\right\|+(1+L)\left\|\nu_{n}-T \nu_{n}\right\| .
\end{aligned}
$$

Since $\lim _{n \rightarrow \infty} t_{n}=\lim _{n \rightarrow \infty} \frac{t_{n}}{\alpha_{n}}=0$, and since $\frac{\left\|\nu_{n_{k}}-x_{n_{k}+1}\right\|^{2}}{\alpha_{n_{k}} t_{n_{k}}}$ is bounded, it now follows from (3.17) and (3.18) that

$$
\lim _{k \rightarrow \infty}\left\|T \nu_{n_{k}}-\nu_{n_{k}}\right\|^{2}=0, \text { and } \lim _{k \rightarrow \infty}\left\|x_{n_{k}}-x_{n_{k}+1}\right\|^{2}=0 .
$$

Since $(I-T)$ is demiclosed at 0 , it follows that any weak cluster point of $\left\{\nu_{n_{k}}\right\}_{k=1}^{\infty}$ is in $F(T)$. Furthermore, $\left\{\nu_{n_{k}}\right\}_{k=1}^{\infty}$ and $\left\{x_{n_{k}}\right\}_{k=1}^{\infty}$ have the same set of weak 
cluster points. Since $F(T)$ is closed and convex, then setting $p=P_{F(T)}(0)$ in Lemma 2.1 and using (3.15) we obtain

$$
\liminf _{n \rightarrow \infty} Z_{n} \geq 2 \liminf _{k \rightarrow \infty}\left\langle x_{n_{k}}-p, p\right\rangle=2 \liminf _{k \rightarrow \infty}\left\langle x_{n_{k}}-P_{F(T)}(0), P_{F(T)}(0)\right\rangle \geq 0 .
$$

From (3.19) and (3.14) we now obtain

$$
\limsup _{n \rightarrow \infty}\left\|x_{n}-p\right\|^{2}=\limsup _{n \rightarrow \infty}\left\|x_{n}-P_{F(T)}(0)\right\|^{2}=0 .
$$

Corollary 3.1 Let $H$ be a real Hilbert space and let $T: H \rightarrow H$ be an $L$ Lipschitzian pseudocontractive map with a nonempty fixed point set $F(T)$. Let $\left\{t_{n}\right\}_{n=1}^{\infty},\left\{\alpha_{n}\right\}_{n=1}^{\infty}$ and $\left\{\beta_{n}\right\}$ be sequences in $(0,1)$ satisfying the conditions

(c1) $\lim _{n \rightarrow \infty} t_{n}=0$

(c2) $\sum_{n=1}^{n \rightarrow \infty} t_{n}=\infty$;

(c3) $\alpha_{n} \leq \beta_{n}, n \geq 1$; and $0<\epsilon \leq \beta_{n} \leq b<1$ for some $\epsilon>0$ and for some $b \in\left(0, \frac{1}{\sqrt{1+L^{2}}+1}\right)$;

(c4) $\lim _{n \rightarrow \infty} \frac{t_{n}}{\alpha_{n}}=0$.

Then the modified Ishikawa iteration sequence $\left\{x_{n}\right\}_{n=1}^{\infty}$ generated from an $x_{1} \in$ $H$ by (3.1) converges strongly to $P_{F(T)}(0)$ the least norm element of $F(T)$.

Corollary 3.2 Let $H$ be a real Hilbert space and let $T: H \rightarrow H$ be a $k$-strictly pseudocontractive map with a nonempty fixed point set $F(T)$. Let $\left\{t_{n}\right\}_{n=1}^{\infty},\left\{\alpha_{n}\right\}_{n=1}^{\infty}$ and $\left\{\beta_{n}\right\}$ be sequences in $(0,1)$ satisfying the conditions

(c1) $\lim _{n \rightarrow \infty} t_{n}=0$

(c2) $\sum_{n=1}^{n \rightarrow \infty} t_{n}=\infty$;

(c3) $\alpha_{n} \leq \beta_{n}, n \geq 1$; and $0<\epsilon \leq \beta_{n} \leq b<1$ for some $\epsilon>0$ and for some $b \in\left(0, \frac{1}{\sqrt{1+L^{2}}+1}\right)$, where $L:=\frac{1+\sqrt{k}}{1-\sqrt{k}}$;

(c4) $\lim _{n \rightarrow \infty} \frac{t_{n}}{\alpha_{n}}=0$.

Then the modified Ishikawa iteration sequence $\left\{x_{n}\right\}_{n=1}^{\infty}$ generated from an $x_{1} \in$ $H$ by (3.1) converges strongly to $P_{F(T)}(0)$ the least norm element of $F(T)$.

Corollary 3.3 Let $H$ be a real Hilbert space and let $T: H \rightarrow H$ be an $L$ Lipschitzian $k$-demicontractive map such that $(I-T)$ is demiclosed at 0 . Let $\left\{t_{n}\right\}_{n=1}^{\infty},\left\{\alpha_{n}\right\}_{n=1}^{\infty}$ and $\left\{\beta_{n}\right\}$ be sequences in $(0,1)$ satisfying the conditions

(c1) $\lim t_{n}=0$

(c2) $\sum_{n=1}^{n \rightarrow \infty} t_{n}=\infty$;

(c3) $\alpha_{n} \leq \beta_{n}, n \geq 1$; and $0<\epsilon \leq \beta_{n} \leq b<1$ for some $\epsilon>0$ and for some $b \in\left(0, \frac{1}{\sqrt{1+L^{2}}+1}\right)$;

(c4) $\lim _{n \rightarrow \infty} \frac{t_{n}}{\alpha_{n}}=0$.

Then the modified Ishikawa iteration sequence $\left\{x_{n}\right\}_{n=1}^{\infty}$ generated from an $x_{1} \in$ 
$H$ by (3.1) converges strongly to $P_{F(T)}(0)$ the least norm element of $F(T)$.

Remark 3.1 Our Theorem and Corollaries remain true if $H$ is replaced with a nonempty closed convex subset $K$ of $H$ with $0 \in K$. Furthermore, for arbitrary nonempty closed convex subset $K$ of $H$, our iteration scheme could be appropriately modified with the projection $P_{K}: H \rightarrow K$ to achieve our results.

\section{Acknowledgement}

The work was completed when the first author was visiting the Abdus Salam International Centre for Theoretical Physics (ICTP), Trieste, Italy as an Associate. He is grateful to the Centre for the invaluable facilities at the Centre and for hospitality. The second author made her contributions while visiting the University of Kwazulu Natal, South Africa under the OWSDW (formally TWOWS) Postgraduate Training Fellowship. She is grateful to OWSDW (formally TWOWS) for the Fellowship and to University of Kwazulu Natal for making their facilities available and for hospitality.

\section{REFERENCES}

1. F.E. Browder and W.V. Petryshyn, Construction of fixed points of nonlinear mappings in Hilbert spaces, J. Math. Anal. Appl. 20 (1967) 197-228.

2. S.A. Naimpally and K.L. Singh, Extensions of some fixed point theorems of Rhoades, J. Math. Anal. Appl. 96 (1983), 437-446.

3. T.L. Hicks, J.D. Kubicek, On the Mann iteration process in a Hilbert spaces, J. Math. Anal. Appl. 59 (1977) 498-504.

4. S.. Măruşter, Sur le calcul des zeros dun operateur discontinu par iteration, Canad. Math. Bull. 16 (4) (1973) 541-544.

5. S. Măruşter, The solution by iteration of nonlinear equations in Hilbert spaces, Proc. Amer. Math Soc. 63 (1) (1977) 69-73.

6. C.E. Chidume, Ş. Măruşter, Iterative methods for the computation of fixed points of demicontractive mappings, J. Comput. Appl. Math. 234 (3) (2010) 861-882.

7. D. Boonchari, S. Saejung, Construction of common fixed points of a countable family of $\lambda$-demicontractive mappings in arbitrary Banach spaces, Appl. Math. Comput. 216 (2010) $173-178$.

8. L. Măruşter and Ş. Măruşter, Strong convergence of the Mann iteration for $\alpha$ demicontractive mappings, Math. Comput. Model. 54 (2011) 2486-2492.

9. C.E. Chidume and S.A. Mutangadura, An example on the Mann iteration method for Lipschitz pseudocontractions. Proc. Amer. Math. Soc. 129 (2001) 2359-2363.

10. G. Marino, H.-K. Xu, Weak and strong convergence theorems for strict pseudo-contractions in Hilbert spaces, J. Math. Anal. Appl. 329 (2007) 336-346.

11. A. Genel, J. Lindenstraus, An example concerning fixed points, Israel J. Math. 22 (1) (1975) 81-86.

12. Y. Yao, H. Zhou, Y.-C. Liou, Strong convergence of a modified KrasnoselskiMann iterative algorithm for non-expansive mappings, J. Appl. Math. Comput. 29 (2009) 383-389.

13. P.E. Maingé, Regularized and inertial algorithms for common fixed points of nonlinear operators, J. Math. Anal. Appl. 344 (2008) 876887. 
14. P.E. Maingé, Ş. Măruşter, Convergence in norm of modified Krasnoselski-Mann iterations for fixed points of demicontractive mappings, Appl. Math. Comput. 217 (24) (2011) 98649874.

15. S. Ishikawa, Fixed points by a new iteration method, Proc. Amer. Math. Soc. 44 (1974) 147-150.

16. M.O. Osilike and D.I. Igbokwe, Weak and Strong Convergence Theorems for Fixed Points of Pseudocontractions and Solutions of Monotone Type Operator Equations, Comput. Math. Appli. 40 (2000), 559-567.

17. H. Zegeye, N. Shahzad, M.A. Alghamdi, Convergence of Ishikawas iteration method for pseudocontractive mappings, Nonlinear Anal. 74 (2011) 7304-7311.

18. Q. Liu, The convergence theorems of the sequence of Ishikawa iterates for hemicontractive mappings, J. Math. Anal. Appl. 148 (1990) 55-62.

19. C.E. Chidume and C. Moore, Fixed point iteration for pseudocontractive maps, Proc. Amer. Math. Soc. 127 (1999) 1163-1170.

20. Q. Liu, On Naimpally and Singhs open question, J. Math. Anal. Appl. 124 (1987) 157-164.

21. H. Zhou, Convergence theorems of fixed points for Lipschitz pseudo-contractions in Hilbert spaces, J. Math. Anal. Appl. 343 (2008) 546-556.

22. Y.H. Yao, Y.C. Liou and G. Marino, A hybrid algorithm for pseudo-contractive mappings, Nonlinear Anal. 71 (2009) 4997-5002.

23. Y.C. Tang, J.G. Peng and L.W. Liu, Strong convergence theorem for pseudocontractive mappings in Hilbert spaces, Nonlinear Anal. 74 (2011) 380-385.

24. Qing-bang Zhang and Cao-zong Cheng, Strong convergence theorem for a family of Lipschitz pseudocontractive mappings in a Hilbert space, Math. Comput. Modelling 48 (2008) 480-485.

M.O. Osilike received M.Sc. from University of Nigeria, Nsukka, Nigeria, DICTP from the Abdus Salam International Centre for Theoretical Physics, Trieste, Italy and a Ph.D. from University of Nigeria, Nsukka, Nigeria. He is a Regular Associate of the Abdus Salam International Centere for Theoretical Physics (The Abdus Salam ICTP) and he is currently a professor at University of Nigeria, Nsukka, Nigeria since 1998. His research interest includes fixed point theory and applications and operator equations.

Department of Mathematics, University of Nigeria, Nsukka, Nigeria.

e-mails: osilike@yahoo.com, micah.osilike@unn.edu.ng

F.O. Isiogugu received M.Sc. from University of Nigeria, Nsukka, Nigeria. She is currently a lecturer at University of Nigeria, Nsukka, Nigeria and is concluding her Ph.D. with OWSD (Formaly TWOWS) Sandwich Fellowship with University of Nigeria, Nsukka, Nigeria as home institution and University of KwaZulu Natal, South Africa as host institution. He is working in the area of fixed point theory and applications and operator equations.

Department of Mathematics, University of Nigeria, Nsukka, Nigeria.

e-mail: obifeli2001@yahoo.com

F.U. Attah received M.Sc. from University of Jos, Nigeria. He is currently a lecturer at Akanu Ibian Federal Polytechnic, Uwana, Afikpo, Nigeria and is on a Ph.D. programme at University of Nigeria, Nsukka, Nigeria. He is working on existence and approximation of fixed points of operators and solutions of operator equations.

Department of Mathematics, University of Nigeria, Nsukka, Nigeria.

e-mails: felix.attah@yahoo.com 